\title{
Current advances in using neurotrophic factors to treat neurodegenerative disorders
}

\author{
April M Weissmiller ${ }^{1}$ and Chengbiao $\mathrm{Wu}^{1,2^{*}}$
}

\begin{abstract}
Neurotrophic factors are best known for their roles in both development and continued maintenance of the nervous system. Their strong potential to elicit pro-survival and pro-functional responses in neurons of the peripheral and central nervous system make them good drug candidates for treatment of a multitude of neurodegenerative disorders. However, significant obstacles remain and need to be overcome before translating the potential of neurotrophins into the therapeutic arena. This article addresses current efforts and advances in resolving these challenges and provides an overview of roadmaps for future translational research and neurotrophin-based drug developments.
\end{abstract}

Keywords: Neurotrophin, Neurotrophic factor, BDNF, NGF, Gene delivery, Mimetics

\section{Introduction}

Neurotrophic factors or neurotrophins are a group of growth factors which have been classically described for their ability to regulate differentiation and to support growth during development of the vertebrate nervous system. The family of neurotrophins consists of nerve growth factor (NGF), brain-derived neurotrophic factor (BDNF), neurotrophin 3 (NT3), and neurotrophin 4 (NT4). In order to elicit a survival response, each binds to one member of the tyrosine receptor kinase (Trk) family: NGF binds to TrkA, BDNF and NT4 bind to TrkB, and NT3 binds to TrkC. Each of the neurotrophins can similarly respond through an apoptotic pathway initiated by binding to the $75 \mathrm{kD}$ neurotrophin receptor $\left(\mathrm{p} 75^{\mathrm{NTR}}\right)$. The spatial and temporal balance achieved between neuronal survival and death depends on the overall level of neurotrophin present and the type of receptors that are expressed [1]. In the peripheral nervous system, NGF is the dominant neurotrophic factor, acting on sympathetic and sensory neurons. However, in the central nervous system, BDNF is the predominant neurotrophin utilized due to the abundant expression of TrkB, with NGF providing trophic support specifically

\footnotetext{
* Correspondence: chw049@ucsd.edu

${ }^{1}$ Department of Neurosciences, University of California San Diego, School of Medicine, La Jolla, CA 92093-0649, USA

${ }^{2}$ Department of Neurosciences, University of California San Diego, George

Palade Labs (GPL), Room 337 MC-0649, 9500 Gilman Drive, La Jolla, CA 92093, USA
}

to the basal forebrain cholinergic neurons (BFCNs) which express TrkA. Studies from heterozygous mice expressing reduced levels of NGF and BDNF reveal that these two factors are essential for multiple functions throughout adulthood such as proper memory acquisition, memory retention, long-term potentiation, and cholinergic innervation $[2,3]$.

Since the discovery of NGF in the 1950s [4] a large body of experimental data has pointed to multiple roles for the neurotrophins. Firstly, most neurotrophins are required during development and differentiation, during a time which specific synaptic connections are being made and proper circuits are being formed. Secondly, neurotrophin signaling plays an important role in adulthood at a time in which continued maintenance and modulation of those connections is required for normal brain function.

\section{Neurotrophic signaling pathways}

Although different neurotrophins act on different receptors in the brain, both NGF and BDNF elicit prosurvival and pro-functional responses using essentially the same canonical signaling pathways: the mitogenactivated protein kinase (MAPK) pathway, the phosphatidylinositol 3-kinases (PI3K)/ the protein kinase B (also known as Akt) pathway, and the phospholipase $\mathrm{C}-\gamma$ pathway (Figure 1). Binding of neurotrophic factor causes dimerization and autophosphorylation of the Trk 


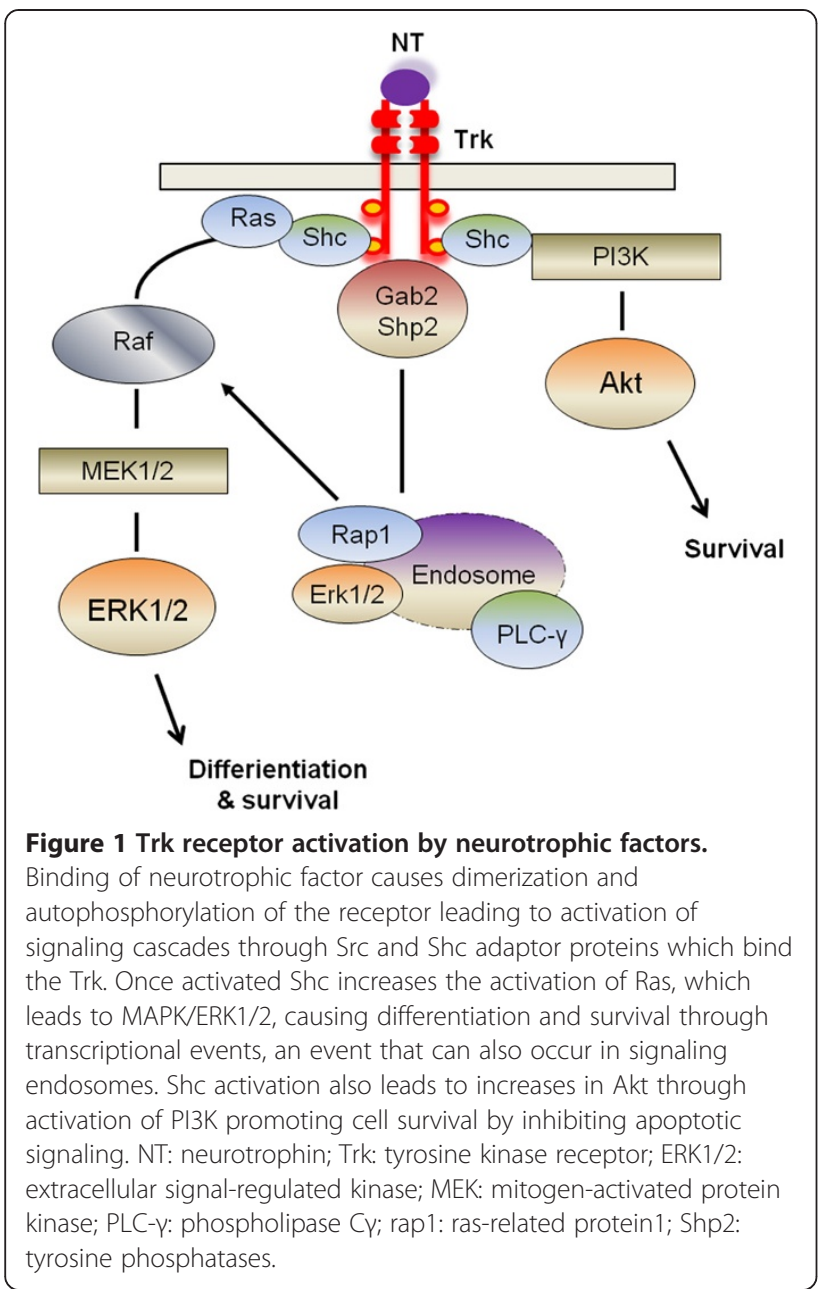

receptor leading to activation of signaling cascades through Src and Shc adaptor proteins which are recruited to the Trk receptor. Once activated Shc increases the activation of Ras, which leads to MAPK/ ERK1/2, causing differentiation and survival through transcriptional events. Activation of this particular pathway is thought to occur as well in a specialized early endosome, the signaling endosome, which has been shown at least for TrkA to contain various signaling molecules such as PLC- $\gamma$, pERK1/2, and the early endosomal protein, Rab5 [5,6]. Transport of the signaling endosome from the axon to the cell body is an important means for transmitting trophic signals to the neuronal soma $[7,8]$. For sustained MAPK activation, Trk activates the scaffolding proteins Gab2/Shp2 and involves the small $\mathrm{G}$ protein, Rap1 on the endosome as well [9]. Shc activation also leads to increases in Akt through activation of PI3K promoting cell survival by inhibiting apoptotic signaling, even though this activation is thought to occur more at the cell surface rather than on intracellular endosomes [10]. These different signaling pathways that are activated by neurotrophins work together to support normal neuronal function and to prevent neuronal cellular death.

\section{Neurotrophins and neurodegenerative diseases}

Given the critical role played by neurotrophins in regulating neuronal functions, it is not surprising then that a significant number of psychiatric and neurodegenerative disorders is associated with altered NGF and BDNF levels and with changed expression of their receptors. For example, neurodegenerative phenotypes similar to Alzheimer's disease (AD) are observed in a mouse model in which half of the NGF level is neutralized by antibodies [11]. In fact, the brains of $\mathrm{AD}$ patients and aged rats show reduced NGF levels in BFCNs [12-14]. Another neurodegenerative disorder, Down's syndrome (DS), exhibits similar NGF signaling deficits in the same region of the brain [15]. Neurotrophins undoubtly have a strong role in preventing cellular death of BFCNs.

The key role for NGF was discovered in early studies on transected fimbria in which administering NGF upon transection was able to markedly reduce cholinergic neuron death, which was typically induced by the procedure [16]. In addition, NGF administration was found to partially reduce cholinergic atrophy in aged rodents [17]. However, to complicate these neurodegenerative disorders further, alterations in BDNF and its receptor are seen in two very important areas that control spatial memory and higher cognitive function: the frontal cortex (FC) and the entorhinal cortex (EC). Alterations in BDNF in these neurons and the overall selective vulnerability of specific areas to degeneration are seen not only in $\mathrm{AD}$, DS, and normal aging, but also other disorders of the brain pointing to multiple roles for BDNF in particular. Both protein and mRNA levels of BDNF are decreased in dopaminergic neurons of the substantia nigra [18], the neurons most vulnerable in Parkinson's disease. BDNF has been shown to have survival role here and alterations in BDNF most likely contribute to the disease [19]. In a similar manner, in Huntington's disease, BDNF transport from cortical to striatal neurons is deficient, contributing to selective loss of striatal neurons and voluntary muscle movements in patients with the disease $[20,21]$. Moreover, BDNF levels are thought to play an important role in susceptibility of nonneurodegenerative diseases. For various psychiatric disorders like bipolar, depression, anxiety, and schizophrenia, it has been shown that there are abnormal increases and decreases in levels of BDNF throughout the brain and in plasma [22-24]. Strong evidence for the link between these disorders to BDNF specifically originates from data from patients carrying a BDNF variant gene, which contains a methionine mutation in the prodomain. Evidence from these subjects and mouse models carrying the 
mutation shows smaller hippocampal volumes, along with decreased activity-dependent BDNF release [22].

While it is still unclear as to why certain areas of the brain are more vulnerable in various disorders over other areas of the brain, one effect that is certain is that the synaptic loss and neuronal dysfunction in these areas lead to detrimental changes to overall synaptic transmission [25-27]. Indeed, vulnerable areas in the brain which are impacted the most in many of the diseases mentioned above show a decrease in neuronal size and number, along with reduced expression of neurotransmitter molecules and receptors in response to the decreased trophic support [28]. It is conceivable that cellular and intracellular changes to neurons, induced by alterations in signaling cascades, can impair neuron's ability to function properly. Alterations in any component along the signaling/survival pathways could potentially exacerbate the deficit in trophic support for neurons, resulting in their dysfunction either locally and/or on a circuit level.

The well documented role for neurotrophic factors to prevent cell death and to maintain cellular function has led scientists to investigate their translational benefit(s). To date, the potential beneficial effect of neurotrophins, NGF and BDNF, in particular, have been explored in light of several neurodegenerative disorders, including but not limited to AD, Amyotrophic lateral sclerosis (ALS) [29], Huntington disease [30], Parkinson's Disease and even obesity [31] (Table 1).

\section{Challenges in neurotrophin-based therapy}

Although there are strong rationales suggesting that increasing supply of neurotrophins to degenerating neurons may be a potent way to restore neuronal function in neurodegenerative conditions, delivering neurotrophins into the brain has proven to be a non-trivial matter. Notoriously, CNS diseases are difficult to treat due to the presence of the blood brain barrier (BBB) that makes it almost impossible for large proteins and complex compounds to cross from the blood into the brain. In addition, the cortical and subcortical circuits of the brain are interconnected resulting in crosstalk among multiple regions, so coming up with a treatment strategy that selectively targets affected neurons only, but not those unaffected ones, is a great challenge that has to be carefully considered. To further compound these issues, neurotrophins are relatively large, polar molecules that cannot readily cross $\mathrm{BBB}$ and therefore must be administered directly into the central nervous system (CNS). Indeed, all current delivery strategies involve invasive procedures as discussed below.

\section{Infusion of neurotrophins by direct intracerebroventricular (ICV) injection}

To bypass the inability of neurotrophins to cross BBB, purified neurotrophins can be directly infused to the brain by intracerebroventricular (ICV) injection. This delivery route is particularly suitable for NGF to treat BFCN degeneration, since BFCNs extend their axons throughout the hippocampus and neocortex. NGF that is infused into the lateral ventricle can act on the TrkA receptor located at the axonal termini to retrogradely transmit trophic support signal for BFCNs. This approach has been proven especially effective in preventing loss of BFCNs in rodents associated with lesions and aging as mentioned above. However, clinical trial with NGF infusion showed that, although long-term NGF administration by ICV injection may cause certain potentially beneficial effects, the intraventricular route of administration is also associated with significant side effects [33], such as hyperinnervation of cerebral blood vessels [34], hypophagia [33,35], Schwann cell hyperplasia with sprouting of sensory and sympathetic neurons [36], and neuropathic pain [33]. As such,

Table 1 Neurotrophic factors that are currently under study for treatment of various disorders

\begin{tabular}{llll}
\hline & Neurotrophic factor & Target neurons & Current status \\
\hline ALS & NGF and BDNF & Motor neurons & Recruiting for Phase 1 and Phase 2 \\
\hline Parkinson's disease & GDNF/neurturin & Striatal neurons & $\begin{array}{l}\text { Some Phase } 1 \text { complete, ongoing } \\
\text { in Phase } 1 \text { and Phase 2 }\end{array}$ \\
\hline Huntington's disease & BDNF & Striatal neurons & Pre-clinical \\
\hline Alzheimer's disease & NGF and BDNF & Cholinergic neurons, entorhinal neurons & Ongoing in Phase 1 \\
\hline Down Syndrome & NGF & Cholinergic neurons & Pre-clinical \\
\hline Spinal Cord Injury & BDNF and NT-3 & Site of injury & Pre-clinical \\
\hline Obesity & BDNF & Hypothalamus & Pre-clinical \\
\hline $\begin{array}{l}\text { Lysosomal storage } \\
\text { disorders }\end{array}$ & BDNF & Various in CNS & Pre-clinical \\
\hline Sensory neuropathies & NGF & Sensory and sympathetic neurons & Phase 2 completed \\
\hline Supranuclear Palsy & GDNF & Various in CNS & Phase 2 completed
\end{tabular}

Current status defines Phase trials that have either been completed or are underway [32]. Pre-clinical status was assigned to each if the neurotrophic factor has been shown to rescue neuronal functioning in target neurons in rodent and primate models of disease. 
these side effects may cause serious concerns in limiting the dose of infused NGF, thus providing only little therapeutic benefit.

NGF involvement in pain is stemmed from its ability to activate the nociceptive response in sensory neurons [37]. NGF as a therapeutic tool has been particularly impacted by this characteristic, even in attempt to treat peripheral neuropathies such as diabetic and HIVinduced neuropathy, two disorders that do not have the delivery barriers to overcome like those of the CNS. Clinical trials with NGF treatment of these two types of neuropathies have to be terminated due to the fact that severe pains were induced in patients, even though symptoms associated with both disorders were ameliorated in early Phase II studies [38,39]. Even healthy volunteers administered with NGF will begin to feel hyperalgesia at the injection site after 3 hours, with worsening effects over the course of three days [40].

Current efforts with infusion of other neurotrophins have yielded similarly disappointing results. For example, to increase the delivery of BDNF, one study has used intrathecal infusion of $\mathrm{N}$-terminal pegylated BDNF after spinal cord injury. While the authors were able to show that pegylated BDNF was able to reach the spinal cord and induce expression in that area, they saw no improved axonal response or locomotor recovery, suggesting the amount of BDNF that was delivered was still insufficient [41]. In a separate study, although enhanced delivery of BDNF to the CNS was achieved intravenously using a combination of pegylation and conjugation to antibodies targeting the transferrin receptor of $\mathrm{BBB}$, in vivo data from this dual approach is still lacking [42]. Intraputamenal infusion of glia-derived neurotrophic factor (GDNF) in Rhesus monkeys has also led to reduced food consumption and weight loss, meningeal thickening and Purkinje cell loss in the cerebellum [43]. More importantly, GDNF infusion provided no significant benefit to human patients with Parkinson's disease [44]. This reoccurring theme of side effects without significant benefit of treatment has also been shown with intrathecal infusion of recombinant BDNF in patients with ALS $[29,45]$.

\section{Neurotrophin-producing cell transplantation}

To circumvent the lack of significant therapeutic benefits in combination with serious adverse effects associated with the infusion approach, other methods are designed to achieve more targeted delivery of neurotrophins directly to those populations of neurons affected in disease. This would allow for more controlled and increased dosing while potentially eliminating side effects through avoiding unknown interactions of the neurotrophin. Currently, two approaches of direct delivery of neurotrophic factor into subcortical sites of the brain have been developed and practiced: transfer of cells modified to express neurotrophic factor and delivery of an engineered viral vector encoding the neurotrophic factor protein. The first technique involves establishing cell lines, preferably from the donor host, to express the neurotrophic factor through transfection and selection using vectors containing the gene of interest. Once expression of the gene is assessed and optimized, the cells can be transferred into brain regions to function locally in providing neurotrophic factor (Figure 2). Early proof-of-principle studies for this approach were carried out in 1987 by Gage and colleagues who first established donor rat fibroblast cells to express a prototype HPRT vector then grafted these cells into several regions of the rat brain. They found that HPRT enzymatic activity in the grafted cells remained high for at least 7 weeks after transfer [46]. Following this study, genetically modified fibroblasts secreting NGF were implanted into the brains of rats with fimbria lesions. Not only were the transplanted cells able to survive and produce NGF, they were able to prevent cholinergic loss and cause the surviving neurons to sprout axons towards the direction of NGF-secreting fibroblasts, an indication that the neurons were functioning properly [47]. Similar studies in primate and nonhuman primates also showed that genetically modified cells from various cell lines (baby hamster kidney and primary cells) were able to rescue cholinergic functioning in injured neurons [48-50]. In addition, this type of gene therapy has been used in both rodent and primate aging models to show that age related reductions in neuronal functioning and memory impairment can be ameliorated through delivery of genetically modified cells that express NGF [51-53]. More importantly, implanted cells sustained NGF production for at least 8 months in the primate brain, and furthermore, administration of NGF in this manner did not elicit those adverse side effects that were seen in infusion studies $[52,53]$, indicating that direct gene delivery could offer a large therapeutic benefit in disease. These findings and ensuing preclinical studies have laid the groundwork that led to the first human clinical trial of NGF gene delivery.

At the beginning of 2001, eight subjects both male and female in early stage AD were enrolled. Primary autologous fibroblasts derived from each subject were genetically modified to produce human NGF using retroviral vectors. Once NGF production was established the cells were injected into the basal forebrain of the subjects either unilaterally or bilaterally. Of those that safely received the NGF delivery, the mean Mini-Mental Status Examination (MMSE) scores showed a mean rate-ofdecline reduction of $51 \%$ over a period of 22 months, and an even higher reduction during the 6-18 months when NGF production remained robust. In addition, there were cognitive improvements and increased PET 


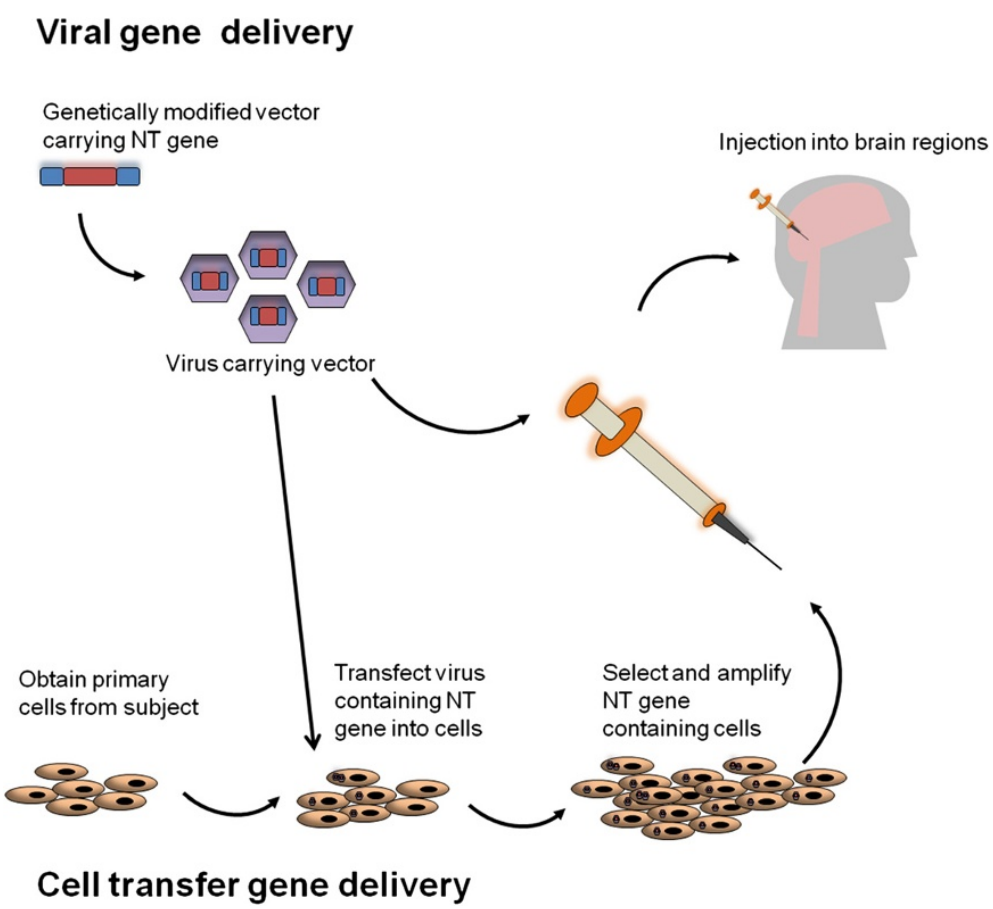

Figure 2 Gene delivery techniques currently being used to deliver neurotrophin to various sites in the nervous system. Direct viral gene delivery of neurotrophin (NT) gene occurs through insertion of the neurotrophin into a viral vector and then placement of the viral vector into a host virus, such as adeno-associated virus or lentivirus. Virus is then directly injected into the brain area(s) through surgical techniques. Cell transfer gene delivery first involves obtaining host cells, preferably from the subject and then transfecting them with virus containing the neurotrophin gene. Once selection and amplification of genetically modified cells is performed, and production of the neurotrophin is confirmed, those cells are then injected or grafted into the brain area(s) through similar surgical techniques.

scan activity in several areas of the brain. Post-mortem analysis of one subject which died 5 weeks after NGF delivery confirmed that there was robust NGF expression in the cell grafts and that cholinergic axons showed sprouting. Overall this study provided the first clinical evidence that directed neurotrophic factor delivery could provide therapeutic benefit without side effects commonly associated with neurotrophic factor infusion. Only hemorrhages in two subjects were observed during injection that may be due to unwanted movements during the procedure. One patient did not recover and died shortly after surgery. General anesthesia has been since adopted to mitigate the problem [54]. Currently, a Phase II clinical trial with this approach is underway.

This technique has also been applied successfully for grafting of BDNF and NT-3 in the treatment of spinal cord injuries. Although not yet performed in human patients, fibroblasts that were modified to express BDNF or GDNF and NT-3 and were grafted into sites of spinal cord injury induced sustained regenerative and sprouting responses into the sites of injury in rats $[55,56]$. Overall direct gene delivery in the clinical setting may prove to have the most beneficial impact yet, this type of procedure remains an invasive technique. Furthermore, although grafted cells have been shown to be functional for up to one year after implantation, subsequent injections may have to be given over the course of a subjects lifetime in order to sustain benefits from the treatment. Moreover, the long term effect(s) of the presence of the large number of fibroblasts in the brain needs to be fully evaluated.

\section{Viral vector-mediated gene delivery}

Due to advances in molecular research in the past decade, viral vector-mediated gene delivery may prove to be a more optimal approach (Figure 2). Delivery of a virus would confer a permanent change in the ability of the neuron to make its own neurotrophic factor, leading to a single injection at the site instead of multiple injections, therefore decreasing the invasiveness. Intrastriatal injection of adeno-associated virus (AAV) vector encoding an enzyme essential in the production dopamine, aromatic L-amino acid decarboxylase (AADC), into MPTPlesioned non-human primates resulted in expression of the enzyme for at least six years [57]. Even more appealing in viral delivery is that the cumbersome cell preparation associated with the cell transfer technique would be eliminated and that AAV vectors do not express their 
own proteins and therefore would not elicit an immune response. To date, viral delivery has been used and evaluated in a number of rodent, primate and human subject studies, particularly for Parkinson's disease (PD). A hallmark of PD is specific dopaminergic loss in the striatum, leading to neuronal and motor dysfunction. Viral gene delivery of AAV encoding AADC was shown to provide eight years of clinical improvement in non-human primates, one of the longest in vivo studies that have been performed thus far [58]. Similarly, viral delivery of GDNF by lentivirus reversed motor deficits in MPTP-treated monkeys and prevented nigrostriatal degeneration [59]. AAV-mediated delivery of an analog of GDNF, neurturin, has also been shown to be neuroprotective for dopaminergic neurons in rats [60]. Studies have demonstrated that injection of the neurturin viral vectors is safe, tolerable and could potentially lead to improvements in motor functioning of actual Parkinson's disease patients at 1 year and in rhesus macaques $[61,62]$. However, as with cell-mediated gene delivery, a small number of human subjects that were given the injection suffered from intracranial hemorrhages [63], indicating that more surgical training and care, perhaps even better injection techniques, need to be adapted to make this type of treatment more applicable.

Viral treatment has also been explored for treating other disorders such as the lysosomal storage disease, late infantile neuronal ceroid lipofuscinosis [64] in which child subjects demonstrated a reduced rate of neurological decline. In addition, administration of a lentiviral construct expressing BDNF into rodent and primate models of AD showed improved cell signaling and a restoration of learning and memory, while reversing synaptic loss [65]. Lentiviral NGF gene delivery in rats has been just as beneficial in preventing cholinergic neuron loss upon fimbria-fornix lesion injury [66]. Currently ongoing and future clinical trials in human subjects using both BDNF and NGF viral delivery should inform about their safety and efficacy, and their potential benefits.

\section{Neurotrophin-peptide mimetics/ small molecules with neurotrophic properties}

It is worth mentioning that many of the challenges facing either direct infusion of neurotrophic factor or cell-, viral vector-mediated gene delivery methods may be overcome with small molecules that target the receptor for the neurotrophic factor instead of introducing the neurotrophic factor itself. This would allow for specific activation of only one type of receptor, such as TrkA or $\operatorname{TrkB}$ and not $\mathrm{p} 75$, or vice versa, potentially alleviating the side effects. To this end, the discovery and use of peptide mimetics, short peptides that have improved bioavailability and lower degree of proteolysis [67], and small molecules ligands for the Trk receptors [68] have attracted intensive interest. A potent peptide mimetic of BDNF has been shown to activate TrkB, promoting neuronal survival in embryonic chick dorsal root ganglion sensory neurons [69]. Also, small molecule BDNF mimetics have high potency and specificity towards TrkB and can promote neuronal survival as well, while also inducing differentiation and synaptic function in cultured hippocampal neurons [70]. When administered to mouse models of $\mathrm{AD}$, Huntington, and PD, the small molecule was able to rescue cellular death to the same extent of full protein BDNF [70]. Further studies using small molecule mimetics of BDNF confirmed their broad application in both restoring TrkB function and improving respiratory function in mouse models of Rett Syndrome [71] and in facilitating functional recovery after stroke while promoting an increase in the number of neurons adjacent to stroke site [72]. Currently, a number of clinical trials are being carried out using neurotrophic factor mimetics [68]. Results from these trials, especially concerning side effects and efficacy, will broaden and enhance neurotrophic factor -based therapy for treating neurodegenerative disorders.

\section{Combinational therapy using neurotrophins and other small molecules}

Neurodegenerative disorders are very complex diseases. Although neurotrophic factor-based strategies have offered great potential, the biggest unknown is whether such approach by itself is adequate in halting and reversing the course of progression of these diseases.

As years have passed and many clinical trials later, the idea that "a single magic bullet approach" or one drug can act as the sole solution for treating neurodegenerative disorders has proven not very successful. This is highlighted well in the case of Alzheimer's disease. For example, acetyl cholinesterase inhibitors (Aricept) and N-methyl-D-Aspartate (NMDA) receptor antagonists (Mementine) have been approved for the treatment of $\mathrm{AD}$, but both treat symptoms and show only moderate efficacy. Unfortunately, both fail to slow the rate of cognitive decline in $\mathrm{AD}$ patients [73]. Furthermore, another painful lesson came from the recent failure of a Phase III trial using gamma secretase inhibitors to treat $\mathrm{AD}$, a "disease-modifying" compound which has been a sought after drug target for some time [74]. It is clear that various treatments with small molecule drugs such as these, have yielded only modest results at best. Novel small molecules for $\mathrm{AD}$, including disease-modifying gamma secretase modulators, are currently under extensive evaluation for their potential for $\mathrm{AD}$ treatment [75]. Given past failure in monotherapy in this arena, it may become necessary to use a combination of approaches, i.e. combinational therapies, to attack the different disease 
causing mechanisms simultanously. We can envision that by a combinational use of a small molecule with neurotrophins may work synergistically to restore neuronal function and to minimize possible side effects as discussed above.

Going forward, the idea of combinational therapies for treating various neurodegenerative disorders is worth serious consideration, given the fact that so many attempts with monotherapies have not yielded any success. For many non-neurodegenerative disorders co-therapies targeting multiple disease pathways and symptoms are actively being used and evaluated. For rheumatoid arthritis, disease modifying antirhematic drugs (DMARDS) are used in combination with fast acting glucocorticoids to alleviate the symptoms of inflammation quickly [76]. The combination of DMARDS and glucocorticoids was shown to cause a reduction in both the tolerability and side effects of DMARD infusion alone [76-79]. Moreover combinational therapy using various DMARDS and glucocorticoids together resulted in short and long term improvements when compared to DMARDS alone [76]. For cardiovascular disease involving cholesterol, treatment with statins is the standard. However, statins have shown over time to eventually lead in some cases to regression of the disease [80]. Co-therapy using statins and niacin have shown to lead to significant decreases in disease causing low-density lipids, while raising beneficial high-density lipids $[80,81]$ which may lead to tighter lipid control and therapeutic benefit for those with statintreated cardiovascular disease. Even for diabetes, insulin, which has been the main glucose lowering treatment, has been evaluated in combination with recombinant human insulin-like growth factor I (IGF1), a pathway that if restored can lead to much higher glucose lowering than insulin alone. Subjects receiving both IGF1 and insulin together decreased their insulin need, while those treated with insulin alone had an increase in insulin usage [82]. Examples such as these highlight various properties of combinational therapies in treating a disorder and confirm why co-therapy in neurodegenerative disease may prove to be most successful. First, these examples show that one can quickly relieve symptoms of a disease with one or more drugs while concomitantly treating the disease itself with another. This is important since treating a disease will most likely have a longer time course inherent to its action than solely relieving symptoms. Secondly, combinational therapy using two or more drugs can compensate for one drug's inactivity over time and therefore potentially inhibit regression of the disease. The final property illustrated here is that combinational therapy using two or more proteins/small molecules can work synergistically together so that one or both are needed in lower dose or less frequently, a convenience that someone suffering from an illness would definitely benefit from.

\section{Conclusions}

NGF and its other family members provide potent trophic support to neurons. Their robust effects in rescuing degenerating neurons cannot be matched in this regard by any small molecules or compounds identified thus far. Neurotrophin-based therapies may well prove to be an effective means to combat epidemic neurodegenerative diseases. Yet, many daunting challenges remain to be resolved. Furthermore, it remains to be seen if such strategies that aim at a single target will be sufficient to cure these diseases. In the end, the inherent complexity of neurodegenerative diseases may require combinational therapies that target multiple pathways for effective treatment.

\section{Competing interests}

The authors declare that they have no competing interests.

\section{Authors' contributions}

AW drafted the manuscript, CW critically revised the manuscript. Both authors read and approved the final manuscript.

\section{Acknowledgements}

We would like to thank Dr Steven $L$ Wagner for stimulating discussion on combinational therapy and Eugene Han for help with editing the manuscript. This work was funded by NIH Neuroplasticity of Aging Predoctoral Training Grant to AW; UCSD NIH ADRC Pilot Grant, LLHF and DSRTF to CW.

Received: 8 June 2012 Accepted: 26 July 2012

Published: 26 July 2012

\section{References}

1. Chao MV: Neurotrophins and their receptors: a convergence point for many signalling pathways. Nat Rev Neurosci 2003, 4:299-309.

2. Korte M, Carroll P, Wolf E, Brem G, Thoenen H, Bonhoeffer T: Hippocampal long-term potentiation is impaired in mice lacking brain-derived neurotrophic factor. Proc Natl Acad Sci U S A 1995, 92:8856-8860.

3. Chen KS, Nishimura MC, Armanini MP, Crowley C, Spencer SD, Phillips HS: Disruption of a single allele of the nerve growth factor gene results in atrophy of basal forebrain cholinergic neurons and memory deficits. J Neurosci 1997, 17:7288-7296.

4. Levi-Montalcini R, Hamburger $V$ : Selective growth stimulating effects of mouse sarcoma on the sensory and sympathetic nervous system of the chick embryo. J Exp Zool 1951, 116:321-361.

5. Grimes ML, Beattie E, Mobley WC: A signaling organelle containing the nerve growth factor-activated receptor tyrosine kinase, TrkA. Proc Natl Acad Sci U S A 1997, 94:9909-9914.

6. Delcroix JD, Valletta JS, Wu C, Hunt SJ, Kowal AS, Mobley WC: NGF signaling in sensory neurons: evidence that early endosomes carry NGF retrograde signals. Neuron 2003, 39:69-84.

7. Campenot RB: Local control of neurite development by nerve growth factor. Proc Natl Acad Sci U S A 1977, 74:4516-4519.

8. Campenot RBM, Bronwyn L: Retrograde transport of neurotrophins: fact and function. Wiley Periodicals, Inc 2003, 58:217-229.

9. Wu C, Lai CF, Mobley WC: Nerve growth factor activates persistent Rap1 signaling in endosomes. J Neurosci 2001, 21:5406-5416.

10. Howe CL, Valletta JS, Rusnak AS, Mobley WC: NGF signaling from clathrincoated vesicles: evidence that signaling endosomes serve as a platform for the Ras-MAPK pathway. Neuron 2001, 32:801-814.

11. Capsoni S, Ugolini G, Comparini A, Ruberti F, Berardi N, Cattaneo A: Alzheimer-like neurodegeneration in aged antinerve growth factor transgenic mice. Proc Natl Acad Sci U S A 2000, 97:6826-6831. 
12. Calissano $P$, Matrone $C$, Amadoro $G$ : Nerve growth factor as a paradigm of neurotrophins related to Alzheimer's disease. Dev Neurobio/ 2010, 70:372-383.

13. Venero JL, Knusel B, Beck KD, Hefti F: Expression of neurotrophin and trk receptor genes in adult rats with fimbria transections: effect of intraventricular nerve growth factor and brain-derived neurotrophic factor administration. Neuroscience 1994, 59:797-815.

14. Cooper JD, Lindholm D, Sofroniew MV: Reduced transport of [125I]nerve growth factor by cholinergic neurons and down-regulated TrkA expression in the medial septum of aged rats. Neuroscience 1994, 62:625-629.

15. Cooper JD, Salehi A, Delcroix JD, Howe CL, Belichenko PV, Chua-Couzens J, Kilbridge JF, Carlson EJ, Epstein CJ, Mobley WC: Failed retrograde transport of NGF in a mouse model of Down's syndrome: reversal of cholinergic neurodegenerative phenotypes following NGF infusion. Proc Natl Acad SC U S A 2001, 98:10439-10444.

16. Hefti F: Nerve growth factor promotes survival of septal cholinergic neurons after fimbrial transections. J Neurosci 1986, 6:2155-2162.

17. Fischer W, Wictorin K, Bjorklund A, Williams LR, Varon S, Gage FH: Amelioration of cholinergic neuron atrophy and spatial memory impairment in aged rats by nerve growth factor. Nature 1987, 329:65-68

18. Mogi M, Togari A, Kondo T, Mizuno $Y$, Komure $O$, Kuno $S$, Ichinose $H$, Nagatsu T: Brain-derived growth factor and nerve growth factor concentrations are decreased in the substantia nigra in Parkinson's disease. Neurosci Lett 1999, 270:45-48.

19. Hyman C, Hofer M, Barde YA, Juhasz M, Yancopoulos GD, Squinto SP, Lindsay RM: BDNF is a neurotrophic factor for dopaminergic neurons of the substantia nigra. Nature 1991, 350:230-232.

20. Gauthier LR, Charrin BC, Borrell-Pages M, Dompierre JP, Rangone $H$, Cordelieres FP, De Mey J, MacDonald ME, Lessmann V, Humbert S, Saudou F: Huntingtin controls neurotrophic support and survival of neurons by enhancing BDNF vesicular transport along microtubules. Cell 2004, 118:127-138.

21. Strand AD, Baquet ZC, Aragaki AK, Holmans P, Yang L, Cleren C, Beal MF, Jones L, Kooperberg C, Olson JM, Jones KR: Expression profiling of Huntington's disease models suggests that brain-derived neurotrophic factor depletion plays a major role in striatal degeneration. $J$ Neurosci 2007, 27:11758-11768.

22. $\mathrm{Yu} \mathrm{H}$, Chen $\mathrm{ZY}$ : The role of BDNF in depression on the basis of its location in the neural circuitry. Acta Pharmacol Sin 2011, 32:3-11.

23. Durany N, Michel T, Zochling R, Boissl KW, Cruz-Sanchez FF, Riederer $P$, Thome J: Brain-derived neurotrophic factor and neurotrophin 3 in schizophrenic psychoses. Schizophr Res 2001, 52:79-86.

24. Arnold SE: Cellular and molecular neuropathology of the parahippocampal region in schizophrenia. Ann N Y Acad Sci 2000, 911:275-292.

25. Belichenko PV, Kleschevnikov AM, Masliah E, Wu C, Takimoto-Kimura R Salehi A, Mobley WC: Excitatory-inhibitory relationship in the fascia dentata in the Ts65Dn mouse model of Down syndrome. J Comp Neurol 2009, 512:453-466.

26. Croarkin PE, Levinson AJ, Daskalakis ZJ: Evidence for GABAergic inhibitory deficits in major depressive disorder. Neurosci Biobehav Rev 2011, 35:818-825.

27. Chong SA, Benilova I, Shaban H, De Strooper B, Devijver H, Moechars D, Eberle W, Bartic C, Van Leuven F, Callewaert G: Synaptic dysfunction in hippocampus of transgenic mouse models of Alzheimer's disease: $\mathrm{A}$ multi-electrode array study. Neurobiol Dis 2011,

28. Isacson $\mathrm{O}$, Seo H, Lin L, Albeck D, Granholm AC: Alzheimer's disease and Down's syndrome: roles of APP, trophic factors and ACh. Trends NeurosCi 2002, 25.79-84

29. Ochs G, Penn RD, York M, Giess R, Beck M, Tonn J, Haigh J, Malta E, Traub M, Sendtner M, Toyka KV: A phase I/II trial of recombinant methionyl human brain derived neurotrophic factor administered by intrathecal infusion to patients with amyotrophic lateral sclerosis. Amyotroph Lateral Scler Other Motor Neuron Disord 2000, 1:201-206.

30. Dey ND, Bombard MC, Roland BP, Davidson S, Lu M, Rossignol J, Sandstrom MI, Skeel RL, Lescaudron L, Dunbar GL: Genetically engineered mesenchymal stem cells reduce behavioral deficits in the YAC 128 mouse model of Huntington's disease. Behav Brain Res 2010, 214:193-200.

31. Cao L, Lin EJ, Cahill MC, Wang C, Liu X, During MJ: Molecular therapy of obesity and diabetes by a physiological autoregulatory approach. Nat Med 2009, 15:447-454.

32. ClinicalTrials.gov, http://clinicaltrials.gov/.

33. Eriksdotter Jonhagen M, Nordberg A, Amberla K, Backman L, Ebendal T, Meyerson B, Olson L, Seiger, Shigeta M, Theodorsson E, et al:
Intracerebroventricular infusion of nerve growth factor in three patients with Alzheimer's disease. Dement Geriatr Cogn Disord 1998, 9:246-257.

34. Isaacson LG, Saffran BN, Crutcher KA: Intracerebral NGF infusion induces hyperinnervation of cerebral blood vessels. Neurobiol Aging 1990, 11:51-55.

35. Williams LR: Hypophagia is induced by intracerebroventricular administration of nerve growth factor. Exp Neurol 1991, 113:31-37.

36. Winkler J, Ramirez GA, Kuhn HG, Peterson DA, Day-Lollini PA, Stewart GR, Tuszynski MH, Gage FH, Thal L: Reversible Schwann cell hyperplasia and sprouting of sensory and sympathetic neurites after intraventricular administration of nerve growth factor. Ann Neurol 1997, 41:82-93.

37. Apfel SC: Neurotrophic factors and pain. Clin J Pain 2000, 16:S7-11.

38. Apfel SC: Nerve growth factor for the treatment of diabetic neuropathy: what went wrong, what went right, and what does the future hold? Int Rev Neurobiol 2002, 50:393-413.

39. Apfel SC, Schwartz S, Adornato BT, Freeman R, Biton V, Rendell M, Vinik A, Giuliani M, Stevens JC, Barbano R, Dyck PJ: Efficacy and safety of recombinant human nerve growth factor in patients with diabetic polyneuropathy: A randomized controlled trial. rhNGF Clinical Investigator Group. JAMA 2000, 284:2215-2221.

40. Dyck PJ, Peroutka S, Rask C, Burton E, Baker MK, Lehman KA, Gillen DA, Hokanson JL, O'Brien PC: Intradermal recombinant human nerve growth factor induces pressure allodynia and lowered heat-pain threshold in humans. Neurology 1997, 48:501-505.

41. Ankeny DP, McTigue DM, Guan Z, Yan Q, Kinstler O, Stokes BT, Jakeman LB: Pegylated brain-derived neurotrophic factor shows improved distribution into the spinal cord and stimulates locomotor activity and morphological changes after injury. Exp Neurol 2001, 170:85-100.

42. Pardridge WM, Wu D, Sakane T: Combined use of carboxyl-directed protein pegylation and vector-mediated blood-brain barrier drug delivery system optimizes brain uptake of brain-derived neurotrophic factor following intravenous administration. Pharm Res 1998, 15:576-582.

43. Hovland DN Jr, Boyd RB, Butt MT, Engelhardt JA, Moxness MS, Ma MH, Emery MG, Ernst NB, Reed RP, Zeller JR, et al: Six-month continuous intraputamenal infusion toxicity study of recombinant methionyl human glial cell line-derived neurotrophic factor ( $r$-metHuGDNF in rhesus monkeys. Toxicol Pathol 2007, 35:1013-1029.

44. Lang AE, Gill S, Patel NK, Lozano A, Nutt JG, Penn R, Brooks DJ, Hotton G, Moro E, Heywood P, et al: Randomized controlled trial of intraputamenal glial cell line-derived neurotrophic factor infusion in Parkinson disease. Ann Neurol 2006, 59:459-466.

45. Beck M, Flachenecker P, Magnus T, Giess R, Reiners K, Toyka KV, Naumann M: Autonomic dysfunction in ALS: a preliminary study on the effects of intrathecal BDNF. Amyotroph Lateral Scler Other Motor Neuron Disord 2005, 6:100-103.

46. Gage FH, Wolff JA, Rosenberg MB, Xu L, Yee JK, Shults C, Friedmann T: Grafting genetically modified cells to the brain: possibilities for the future. Neuroscience 1987, 23:795-807.

47. Rosenberg MB, Friedmann T, Robertson RC, Tuszynski M, Wolff JA, Breakefield XO, Gage FH: Grafting genetically modified cells to the damaged brain: restorative effects of NGF expression. Science 1988, 242:1575-1578.

48. Tuszynski MH, Roberts J, Senut MC, U HS, Gage FH: Gene therapy in the adult primate brain: intraparenchymal grafts of cells genetically modified to produce nerve growth factor prevent cholinergic neuronal degeneration. Gene Ther 1996, 3:305-314.

49. Emerich DF, Winn SR, Harper J, Hammang JP, Baetge EE, Kordower JH: Implants of polymer-encapsulated human NGF-secreting cells in the nonhuman primate: rescue and sprouting of degenerating cholinergic basal forebrain neurons. J Comp Neurol 1994, 349:148-164

50. Kordower JH, Winn SR, Liu YT, Mufson EJ, Sladek JR Jr, Hammang JP, Baetge EE, Emerich DF: The aged monkey basal forebrain: rescue and sprouting of axotomized basal forebrain neurons after grafts of encapsulated cells secreting human nerve growth factor. Proc Natl Acad Sci U S A 1994, 91:10898-10902

51. Chen KS, Gage FH: Somatic gene transfer of NGF to the aged brain: behavioral and morphological amelioration. J Neurosci 1995, 15:2819-2825.

52. Smith DE, Roberts J, Gage FH, Tuszynski MH: Age-associated neuronal atrophy occurs in the primate brain and is reversible by growth factor gene therapy. Proc Natl Acad Sci U S A 1999, 96:10893-10898.

53. Conner JM, Darracq MA, Roberts J, Tuszynski MH: Nontropic actions of neurotrophins: subcortical nerve growth factor gene delivery reverses 
age-related degeneration of primate cortical cholinergic innervation. ProC Natl Acad Sci U S A 2001, 98:1941-1946.

54. Tuszynski MH, Thal L, Pay M, Salmon DP, HS U, Bakay R, Patel P, Blesch A, Vahlsing HL, Ho G, et al: A phase 1 clinical trial of nerve growth factor gene therapy for Alzheimer disease. Nat Med 2005, 11:551-555.

55. Blesch A, Tuszynski MH: Transient growth factor delivery sustains regenerated axons after spinal cord injury. J Neurosci 2007, 27:10535-10545.

56. Tobias CA, Shumsky JS, Shibata M, Tuszynski MH, Fischer I, Tessler A, Murray $M$ : Delayed grafting of BDNF and NT-3 producing fibroblasts into the injured spinal cord stimulates sprouting, partially rescues axotomized red nucleus neurons from loss and atrophy, and provides limited regeneration. Exp Neurol 2003, 184:97-113.

57. Bankiewicz KS, Forsayeth J, Eberling JL, Sanchez-Pernaute R, Pivirotto $P$, Bringas J, Herscovitch P, Carson RE, Eckelman W, Reutter B, Cunningham J: Long-term clinical improvement in MPTP-lesioned primates after gene therapy with AAV-hAADC. Mol Ther 2006, 14:564-570.

58. Hadaczek P, Eberling JL, Pivirotto P, Bringas J, Forsayeth J, Bankiewicz KS: Eight years of clinical improvement in MPTP-lesioned primates after gene therapy with AAV2-hAADC. Mol Ther 2010, 18:1458-1461.

59. Kordower JH, Emborg ME, Bloch J, Ma SY, Chu Y, Leventhal L, McBride J, Chen EY, Palfi S, Roitberg BZ, et al: Neurodegeneration prevented by lentiviral vector delivery of GDNF in primate models of Parkinson's disease. Science 2000, 290:767-773.

60. Gasmi M, Herzog CD, Brandon EP, Cunningham JJ, Ramirez GA, Ketchum ET, Bartus RT: Striatal delivery of neurturin by CERE-120, an AAV2 vector for the treatment of dopaminergic neuron degeneration in Parkinson's disease. Mol Ther 2007, 15:62-68.

61. Marks WJ Jr, Ostrem JL, Verhagen L, Starr PA, Larson PS, Bakay RA, Taylor R, Cahn-Weiner DA, Stoessl AJ, Olanow CW, Bartus RT: Safety and tolerability of intraputaminal delivery of CERE-120 (adeno-associated virus serotype 2-neurturin) to patients with idiopathic Parkinson's disease: an openlabel, phase I trial. Lancet Neurol 2008, 7:400-408.

62. Herzog CD, Brown L, Gammon D, Kruegel B, Lin R, Wilson A, Bolton A, Printz M, Gasmi M, Bishop KM, et al: Expression, bioactivity, and safety 1 year after adeno-associated viral vector type 2-mediated delivery of neurturin to the monkey nigrostriatal system support cere-120 for Parkinson's disease. Neurosurgery 2009, 64:602-612. discussion 612-603.

63. Christine CW, Starr PA, Larson PS, Eberling JL, Jagust WJ, Hawkins RA, VanBrocklin HF, Wright JF, Bankiewicz KS, Aminoff MJ: Safety and tolerability of putaminal AADC gene therapy for Parkinson disease. Neurology 2009, 73:1662-1669.

64. Worgall S, Sondhi D, Hackett NR, Kosofsky B, Kekatpure MV, Neyzi N, Dyke JP, Ballon D, Heier L, Greenwald BM, et al: Treatment of late infantile neuronal ceroid lipofuscinosis by CNS administration of a serotype 2 adeno-associated virus expressing CLN2 cDNA. Hum Gene Ther 2008, 19:463-474.

65. Nagahara AH, Merrill DA, Coppola G, Tsukada S, Schroeder BE, Shaked GM, Wang L, Blesch A, Kim A, Conner JM, et al: Neuroprotective effects of brain-derived neurotrophic factor in rodent and primate models of Alzheimer's disease. Nat Med 2009, 15:331-337.

66. Blesch A, Conner J, Pfeifer A, Gasmi M, Ramirez A, Britton W, Alfa R, Verma I, Tuszynski MH: Regulated lentiviral NGF gene transfer controls rescue of medial septal cholinergic neurons. Mol Ther 2005, 11:916-925.

67. Adessi C, Soto C: Converting a peptide into a drug: strategies to improve stability and bioavailability. Curr Med Chem 2002, 9:963-978.

68. Price RD, Milne SA, Sharkey J, Matsuoka N: Advances in small molecules promoting neurotrophic function. Pharmacol Ther 2007, 115:292-306.

69. O'Leary PD, Hughes RA: Design of potent peptide mimetics of brainderived neurotrophic factor. J Biol Chem 2003, 278:25738-25744.

70. Massa SM, Yang T, Xie Y, Shi J, Bilgen M, Joyce JN, Nehama D, Rajadas J, Longo FM: Small molecule BDNF mimetics activate TrkB signaling and prevent neuronal degeneration in rodents. J Clin Invest 2010, 120:1774-1785.

71. Schmid DA, Yang T, Ogier M, Adams I, Mirakhur Y, Wang Q, Massa SM, Longo FM, Katz DM: A TrkB small molecule partial agonist rescues TrkB phosphorylation deficits and improves respiratory function in a mouse model of Rett syndrome. J Neurosci 2012, 32:1803-1810.

72. Han J, Pollak J, Yang T, Siddiqui MR, Doyle KP, Taravosh-Lahn K, Cekanaviciute E, Han A, Goodman JZ, Jones B, et al: Delayed Administration of a Small Molecule Tropomyosin-Related Kinase B Ligand Promotes Recovery After Hypoxic-Ischemic Stroke. Stroke 2012, .
73. Herrmann N, Chau SA, Kircanski I, Lanctot KL: Current and emerging drug treatment options for Alzheimer's disease: a systematic review. Drugs 2011, 71:2031-2065.

74. Lilly Halts Development of Semagacestat for Alzheimer's Disease Based on Preliminary Results of Phase III Clinical Trials. http://newsroom.lilly.com/ releasedetail.cfm?releaseid $=499794$.

75. Kounnas MZ, Danks AM, Cheng S, Tyree C, Ackerman E, Zhang X, Ahn K, Nguyen $\mathrm{P}, \mathrm{Comer} \mathrm{D}, \mathrm{Mao} \mathrm{L}$, et al: Modulation of gamma-secretase reduces beta-amyloid deposition in a transgenic mouse model of Alzheimer's disease. Neuron 2010, 67:769-780.

76. Hoes JN, Jacobs JW, Buttgereit F, Bijlsma JW: Current view of glucocorticoid co-therapy with DMARDs in rheumatoid arthritis. Nat Rev Rheumatol 2010, 6:693-702

77. Augustsson J, Eksborg S, Ernestam S, Gullstrom E, van Vollenhoven R: Lowdose glucocorticoid therapy decreases risk for treatment-limiting infusion reaction to infliximab in patients with rheumatoid arthritis. Ann Rheum Dis 2007, 66:1462-1466.

78. Malysheva OA, Wahle M, Wagner U, Pierer M, Arnold S, Hantzschel H, Baerwald CG: Low-dose prednisolone in rheumatoid arthritis: adverse effects of various disease modifying antirheumatic drugs. J Rheumatol 2008, 35:979-985.

79. Emery P, Fleischmann R, Filipowicz-Sosnowska A, Schechtman J, Szczepanski L, Kavanaugh A, Racewicz AJ, van Vollenhoven RF, Li NF, Agarwal S, et al: The efficacy and safety of rituximab in patients with active rheumatoid arthritis despite methotrexate treatment: results of a phase IIB randomized, double-blind, placebo-controlled, dose-ranging trial. Arthritis Rheum 2006, 54:1390-1400.

80. Michos ED, Sibley CT, Baer JT, Blaha MJ, Blumenthal RS: Niacin and Statin Combination Therapy for Atherosclerosis Regression and Prevention of Cardiovascular Disease Events: Reconciling the AIM-HIGH (Atherothrombosis Intervention in Metabolic Syndrome With Low HDL/ High Triglycerides: Impact on Global Health Outcomes) Trial With Previous Surrogate Endpoint Trials. J Am Coll Cardiol 2012, 59:2058-2064.

81. McKenney JM, Jones PH, Bays HE, Knopp RH, Kashyap ML, Ruoff GE, McGovern ME: Comparative effects on lipid levels of combination therapy with a statin and extended-release niacin or ezetimibe versus a statin alone (the COMPELL study). Atherosclerosis 2007, 192:432-437.

82. Thrailkill KM, Quattrin T, Baker L, Kuntze JE, Compton PG, Martha PM Jr: Cotherapy with recombinant human insulin-like growth factor I and insulin improves glycemic control in type 1 diabetes. RhIGF-I in IDDM Study Group. Diabetes Care 1999, 22:585-592.

doi:10.1186/2047-9158-1-14

Cite this article as: Weissmiller and Wu: Current advances in using neurotrophic factors to treat neurodegenerative disorders. Translational Neurodegeneration 2012 1:14.

\section{Submit your next manuscript to BioMed Central and take full advantage of:}

- Convenient online submission

- Thorough peer review

- No space constraints or color figure charges

- Immediate publication on acceptance

- Inclusion in PubMed, CAS, Scopus and Google Scholar

- Research which is freely available for redistribution 